\title{
Prognostic value of inflammatory markers for detecting anastomotic leakage after esophageal resection
}

\author{
Lukas F. Liesenfeld ${ }^{1 *}$ (D), Peter Sauer², Markus K. Diener ${ }^{1}$, Ulf Hinz ${ }^{1}$, Thomas Schmidt ${ }^{1}$, Beat P. Müller-Stich ${ }^{1}$, \\ Thilo Hackert ${ }^{1}$, Markus W. Büchler ${ }^{1}$ and Anja Schaible ${ }^{1}$
}

\begin{abstract}
Background: Early diagnosis of anastomotic leakage (AL) after esophageal resection is crucial for the successful management of this complication. Inflammatory serological markers are indicators of complications during the postoperative course. The aim of the present study was to evaluate the prognostic value of routine inflammatory markers to predict anastomotic leakage after transthoracic esophageal resection.
\end{abstract}

Methods: Data from all consecutive patients undergoing transthoracic esophageal resection between January 2010 and December 2016 were analyzed from a prospective database. Besides clinicodemographic parameters, C-reactive protein, white blood cell count and albumin were analyzed and the Noble/Underwood (NUn) score was calculated to evaluate their predictive value for postoperative anastomotic leakage. Diagnostic accuracy was measured by sensitivity, specificity, and negative and positive predictive values using area under the receiver operator characteristics curve.

Results: Overall, 233 patients with transthoracic esophageal resection were analyzed, 30-day mortality in this group was 3.4\%. 57 patients (24.5\%) suffered from AL, 176 patients were in the AL negative group. We found significant differences in WBCC, CRP and NUn scores between patients with and without AL, but the analyzed markers did not show an independent relevant prognostic value. For CRP levels below $155 \mathrm{mg} / \mathrm{dl}$ from POD3 to POD 7 the negative predictive value for absence of Al was $>80 \%$. Highest diagnostic accuracy was detected for CRP levels on $4^{\text {th }}$ POD with a cut-off value of $145 \mathrm{mg} / \mathrm{l}$ reaching negative predictive value of $87 \%$.

Conclusions: In contrast to their prognostic value in other surgical procedures, CRP, WBCC and NUn score cannot be recommended as independent markers for the prediction of anastomotic leakage after transthoracic esophageal resection. CRP is an accurate negative predictive marker and discrimination of AL and no-AL may be helpful for postoperative clinical management.

Trial registration The study was approved by the local ethical committee (S635-2013).

Keywords: Esophageal carcinoma, Esophageal resection, Anastomotic leakage, White blood cell count, C-reactive protein, Nun score

*Correspondence: lukas.liesenfeld@med.uni-heidelberg.de 1 Department of Surgery, Heidelberg University Hospital, Im Neuenheimer Feld 420, 69120 Heidelberg, Germany

Full list of author information is available at the end of the article

\section{Background}

Despite advancements in chemotherapy and radiotherapy, surgery remains the only curative treatment option for locally advanced esophageal carcinoma [1]. However, multimodality neoadjuvant regimens are also crucial as they can increase rates of R0 resections, pathological 
complete responses, and local tumor control, which are beneficial for improved overall survival [1]. Surgery for locally advanced esophageal carcinoma is performed according to tumor localization relative to the gastroesophageal junction and using any of the following approaches: transhiatal, transthoracic (Ivor Lewis procedure), or tri-incisional esophagectomy (McKeown procedure [1]).

Improvements in perioperative management and surgical technique have resulted in a steady decrease of postoperative mortality $[2,3]$. However, recent nationwide data in the US showed a higher mortality rate of esophagectomy than that in most contemporary case series (7\% vs. 1-4\%) [4-7]. Further, morbidity continues to be as high as $50 \%[8,9]$. Among the postoperative complications, anastomotic leakage (AL) is the most fatal and frequent cause of postoperative mortality [10]. The incidence of AL following esophageal resection varies widely, but it has been reported to reach as high as 53\% [10-20]. The variations in the leakage rates are also because of lack of a generally accepted, accurate definition of an AL $[21,22]$. Further, a gold standard for diagnosing and managing leakage has not yet been established.

Early AL detection and treatment initiation are important to limit contamination and minimize sepsis and ultimately mitigate leakage-related mortality [23, 24]. Unrecognized leakage results in development of mediastinitis that is associated with high morbidity and mortality $[25,26]$. Thus, early diagnosis of AL before the patients present with symptoms of mediastinitis such as confusion, fever, pain, or cardiorespiratory insufficiency, is crucial. Furthermore, early suspicion of AL may help to exclude patients from fast-track protocols and avoid early oral feeding. However, there is no standardized method for AL management after esophageal resection. Treatment is usually decided on the size of the leak, the degree of local contamination, and severity of the associated system response [27]. The ultimate modality for controlling leakage is surgery with esophageal diversion, but it also has a critical impact on the patient's quality of life [28-32].

Various studies have attempted to identify AL prior to the onset of systemic changes in patient status using several molecular markers [18, 33-39] including white blood cell count (WBCC) and C-reactive protein (CRP). In particular, CRP is increasingly being studied as an early marker for postoperative complications [40]. CRP is an acute-phase protein produced by hepatocytes in response to pro-inflammatory cytokines [41]. CRP levels increase following surgery and commonly peak after $48 \mathrm{~h}$ then decrease thereafter in patients with an uncomplicated postoperative course. Several prospective studies and meta-analyses showed that CRP is a useful marker of
AL after colorectal surgery [42, 43]. Meanwhile, the role of CRP in esophageal resection is less established. Some authors have reported a significant diagnostic value of CRP to detect AL. CRP values of $141 \mathrm{mg} / \mathrm{l}$ to $229 \mathrm{mg} / \mathrm{l}$, particularly on postoperative day (POD) 3 and 4, have been reported to show a high diagnostic accuracy for AL, with an AUC of 0.71 to 0.86 (Table 1) [14, 16-18]. Park et al. showed that CRP has a high prognostic value for detecting $\mathrm{AL}$ in patients without neoadjuvant treatment prior to surgery [19].

Meanwhile, the diagnostic accuracy of WBCC for AL is yet to be evaluated $[10,15]$. Noble and Underwood developed a score consisting of WBCC, CRP, and albumin values on the 4th POD (NUn score) to detect AL after upper gastrointestinal resections with esophageal anastomosis and reported a sensitivity $>95 \%$ [34]. The present study aimed to evaluate and validate the prognostic value of CRP level, WBCC, and NUn score in detecting AL in a well-defined cohort after transthoracic esophageal resection.

\section{Methods \\ Study design and patients}

This single-center retrospective study was approved by the local ethical committee of Medical Faculty Heidelberg. Need for written informed consent was waived owing to the retrospective nature of the study. All consecutive patients undergoing elective transthoracic esophageal resection at our institution between January 2010 and December 2016 were included in the study (Table 2). Data were collected from a prospectively maintained database. The patients were divided into two groups according to the absence (AL-negative) or presence (AL-positive) of AL (Table 2).

\section{Surgical standard of esophageal resection}

A combination of midline laparotomy and right thoracotomy was performed for esophageal resection combined with two-field lymphadenectomy. All patients had an immediate reconstruction using either tubularized gastric conduit or colon. Patients were usually extubated in the operating room and transferred to the intensive care unit. Patient management during the postoperative period was standardized. While only water and tea were allowed from days 1-4, oral intake was increased stepwise from day 5 onwards. Data recorded included demographics, tumor characteristics, type of reconstruction, postoperative complications and mortality.

\section{Assessment of AL}

AL was suspected according to the presence of the following clinical signs or pathologic systemic response: fever, increased white blood cell count or CRP levels in 


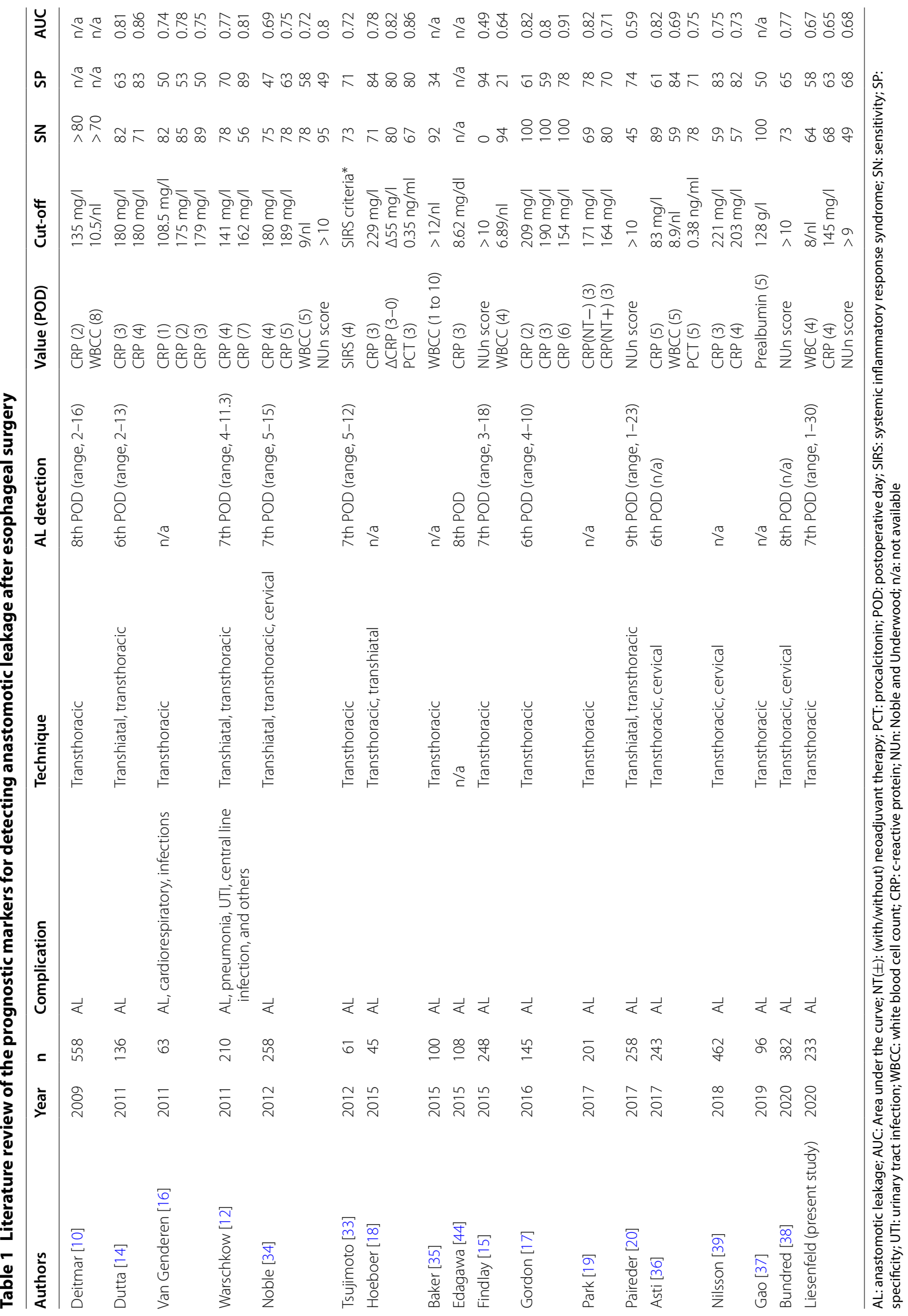


Table 2 Patient characteristics

\begin{tabular}{llll}
\hline & Total (\%) & AL-negative & AL-positive \\
\hline $\mathrm{N}$ & $233(100 \%)$ & $176(75.5 \%)$ & $57(24.5 \%)$ \\
Sex & $194(83.26 \%)$ & $144(61.8 \%)$ & $50(21.5 \%)$ \\
$\quad$ Male & $39(16.74 \%)$ & $32(13.7 \%)$ & $7(3 \%)$ \\
Female & $2(0.9 \%)$ & & \\
Tumor type & $170(72.9 \%)$ & & \\
None & $60(25.8 \%)$ & & \\
AEG I-III & $1(0.4 \%)$ & $136(74.7 \%)$ & $46(25.3 \%)$ \\
SCC & $182(78.11 \%)$ & & \\
NEC & & & 0.71 \\
Neoadjuvant treatment ${ }^{a}$ & $229(98.3 \%)$ & & \\
Reconstruction & $4(1.7 \%)$ & $7 \pm 14.2$ & $19 \pm 27.4$ \\
Gastric tube & $7 \pm 20.1$ & $17 \pm 15.5$ & $46 \pm 30.7$ \\
Colon & $19 \pm 24.6$ & $2(0.9 \%)$ & $6(2.5 \%)$ \\
Length of ICU stay [days] & $8(3.4 \%)$ & & $<0.001$ \\
Length of hospitalization [days] & & \\
30-day mortality & & & \\
\hline
\end{tabular}

AL: anastomotic leakage; AEG: adenocarcinoma of esophagogastric junction; SCC: squamous cell carcinoma; NEC: neuroendocrine carcinoma; ICU: intensive care unit

a Radio- and/or chemotherapy

the absence of pulmonary or urinary tract infection, development of organ failure, including respiratory or renal failure, sepsis, poor neurologic function, or gastrointestinal content within the pleural drains [27]. In these cases, AL was confirmed according to extravasation of oral contrast at computed tomography scan and/or visualization of anastomotic defect at upper gastrointestinal endoscopy and/or surgical exploration. For the endoscopic detection of AL, a flexible video endoscopy system (i.e., GIF H-180, Olympus, Tokyo, Japan) was used by an endoscopic specialist.

Serial routine blood samples were taken daily in the pre- and postoperative period. Inflammatory parameters (i.e., WBCC and CRP levels) were analyzed from the day of operation until the 7th POD. The albumin level on 4th POD was also acquired to calculate the NUn score. The NUn score was calculated using the following formula: NUn $\quad$ score $=11.3894+(0.005 \times \mathrm{CRP})+0.186 \times \mathrm{WB}$ CC) $-(0.174 \times$ albumin $)$.

\section{Statistical analysis}

Postoperative inflammatory laboratory values were compared using Wilcoxon-Mann-Whitney test. P value $<0.05$ was considered significant. Detection accuracy was determined using the area under the receiver operator characteristics curve (AUROCC) [45, 46]. It is a direct measure for diagnostic accuracy of a test, with an AUC $>0.7$ being regarded as a clinically useful test [46] AUC was calculated using the trapezoidal rule, and an AUC of 0.7-0.8 was considered acceptable, 0.8-0.9 excellent, and $>0.9$ outstanding [46]. The optimal cut-off value for WBCC, CRP level, and NUn score was calculated using the Youden index (Youden index=Sensitivity + Specificity -1$)$. Data is given as median \pm standard deviation or mean with range.

\section{Results}

Patient characteristics

We evaluated 233 consecutive patients who underwent elective transthoracic esophageal resection at our institution between January 2010 and December 2016. The majority of the patients were male $(\mathrm{n}=194,83.3 \%)$. The patient and tumor characteristics, as well as the perioperative and intraoperative details, are shown in Table 2. Transthoracic esophageal resection was performed due to malignant disease in $99.1 \%$ of patients $(72.9 \%$ adenocarcinoma, $25.8 \%$ squamous carcinoma, $0.4 \%$ neuroendocrine carcinoma). Overall, 182 patients (78.1\%) received neoadjuvant treatment (chemo- and/or radiotherapy) prior to surgery. The AL-negative and the ALpositive groups included $176(75.5 \%)$ and 57 (24.5\%) patients, respectively. There were no significant differences in clinicodemographic characteristics between the two groups.

Most of the patients ( $\mathrm{n}=229,98.3 \%)$ underwent reconstruction with a gastric pull-up and intrathoracic anastomosis. Only 4 patients (1.7\%) had a colonic interposition. The median time to AL diagnosis was $7( \pm 6.4)$ days, and AL was diagnosed between the 1st to 30th POD (Fig. 1). For further analysis the 7 patients diagnosed with AL 


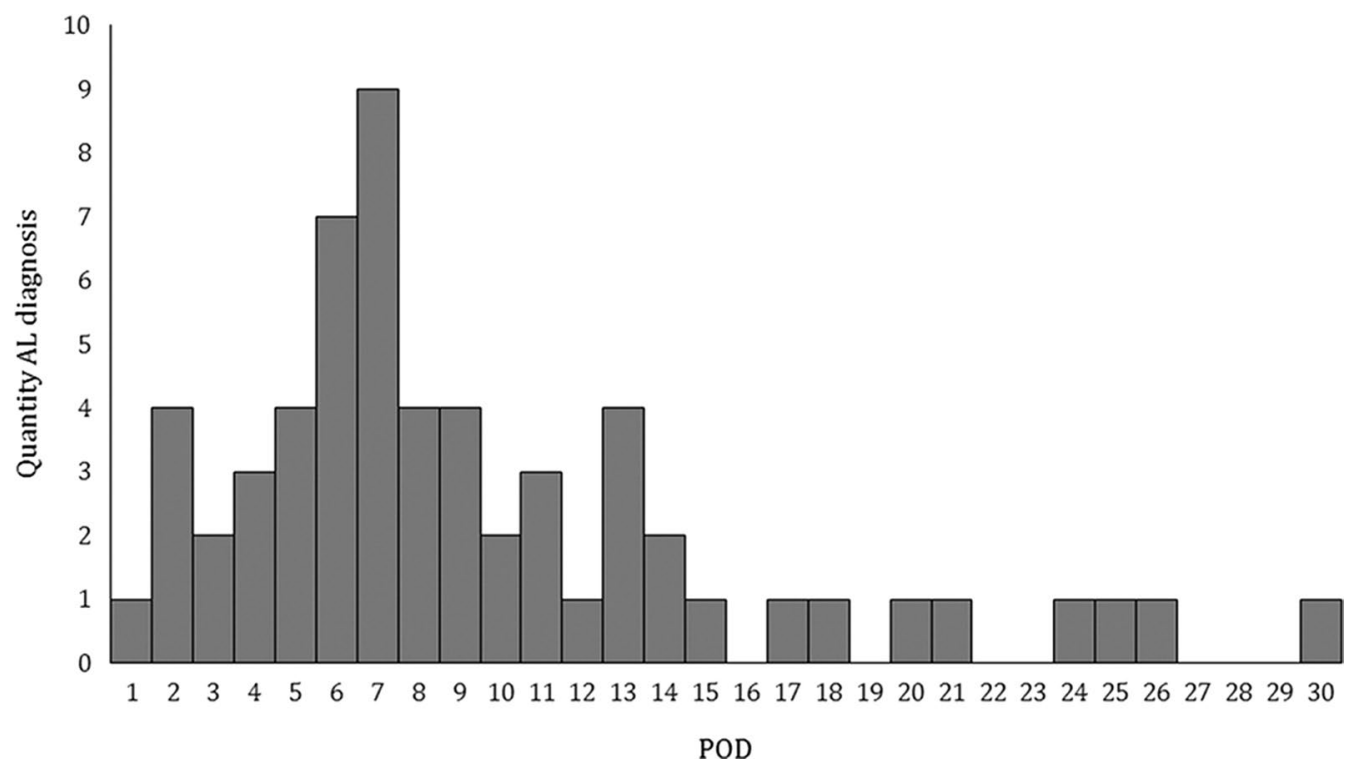

Fig. 1 Histogram of quantity of AL by timepoint of diagnosis as postoperative day (POD). AL was most frequently diagnosed on 7th POD and overall approximately $50 \%$ were diagnosed prior 8 th POD

prior 4th POD were excluded due to assumed technical failure as source of AL. However, the withdrawal of these patients in the significances of the analyzed endpoints of the study showed no difference. There were no significant correlations between the occurrence of $\mathrm{AL}$ and sex $(\mathrm{p}=0.3)$ and neoadjuvant therapy $(\mathrm{p}=0.71)$. As expected, the length of intensive care unit stay $(19 \pm 27.4$ days vs. $7 \pm 14.2$ days) and hospitalization ( $46 \pm 30.7$ days vs. $17 \pm 15.5$ days) were significantly higher in patients with AL $(\mathrm{p}<0.001)$.

\section{WBCC}

The mean WBCC level from the 1st to 7th POD in the AL-positive and the AL-negative group is shown in Fig. 2a. WBCC peaked on the 1st to 2nd POD, then consecutively decreased in both groups. However, the mean WBCC on the 3rd to 7th POD was significantly higher in the AL-positive group than that in the AL-negative group (range of means $9.8 / \mathrm{nl}$ to $12.7 / \mathrm{nl}$ vs.7.8/nl to $10.8 / \mathrm{nl}$ ). The sensitivity and specificity rates of WBCC ranged from 44 to $65 \%$ and from 53 to $76 \%$, respectively (Table 3 ). Best discrimination was possible on the 4th POD with a cut-off value of $8 / \mathrm{nl}$; this had a negative predictive value (NPV) of $84.6 \%$ and a positive predictive value (PPV) of 31.3\% (Fig. 3a). AUC values remained below 0.7. There were no significant differences in the absolute alterations of WBCC (Table 4).

Furthermore, we evaluated the absolute value and relative changes of WBCC in patients with AL 1 to 2 days prior diagnosis. WBCC on the day and 2 days before diagnosis showed a mean increase of $31 \%$ (range, $-28 \%$ to $186 \%$ ) and $19 \%$ (range, $-19 \%$ to $187 \%$ ), respectively. However, in $18.2 \%$ and $24 \%$ of the patients, the WBCC decreased 1 and 2 days prior to the diagnosis of AL. Evaluating WBCC in subpopulations with and without neoadjuvant treatment did not reveal better accuracy to discriminate AL (Additional file 1: Table S1 and Additional file 2: Table S2).

\section{CRP}

The mean CRP level on the 1st to 7th POD for patients in the AL-positive and the AL-negative groups is shown in Fig. 2b. The CRP levels increased in both groups on the 1st and 2nd POD. However, while starting to decrease from the 3rd POD in the AL-negative group, CRP-levels remained high in the AL-positive group. There were significant differences in the CRP level from the 2nd to 7 th POD between the two groups. The mean CRP values from the 2nd to 7th POD in the AL-negative group ranged from $105 \mathrm{mg} / \mathrm{l}$ to $161 \mathrm{mg} / \mathrm{l}$ and from $162 \mathrm{mg} / \mathrm{l}$ to $181 \mathrm{mg} / \mathrm{l}$ in the AL-positive group. The sensitivity and specificity rates ranged from 46 to $72 \%$ and from 44 to $71 \%$, respectively (Table 3 ). Best discrimination was possible on the 4th POD with a cut-off value of $145 \mathrm{mg} / \mathrm{l}$ (AUC, 0.65; NPV, 86.9\%; PPV, 35.1\%; Table 3, Fig. 3b). There were significant differences in the absolute alterations of CRP (Table 4, Fig. 3c), but the sensitivity ranged from 44 to $68 \%$, while the specificity ranged from 51 to $75 \%$, with AUC values below 0.7 . 

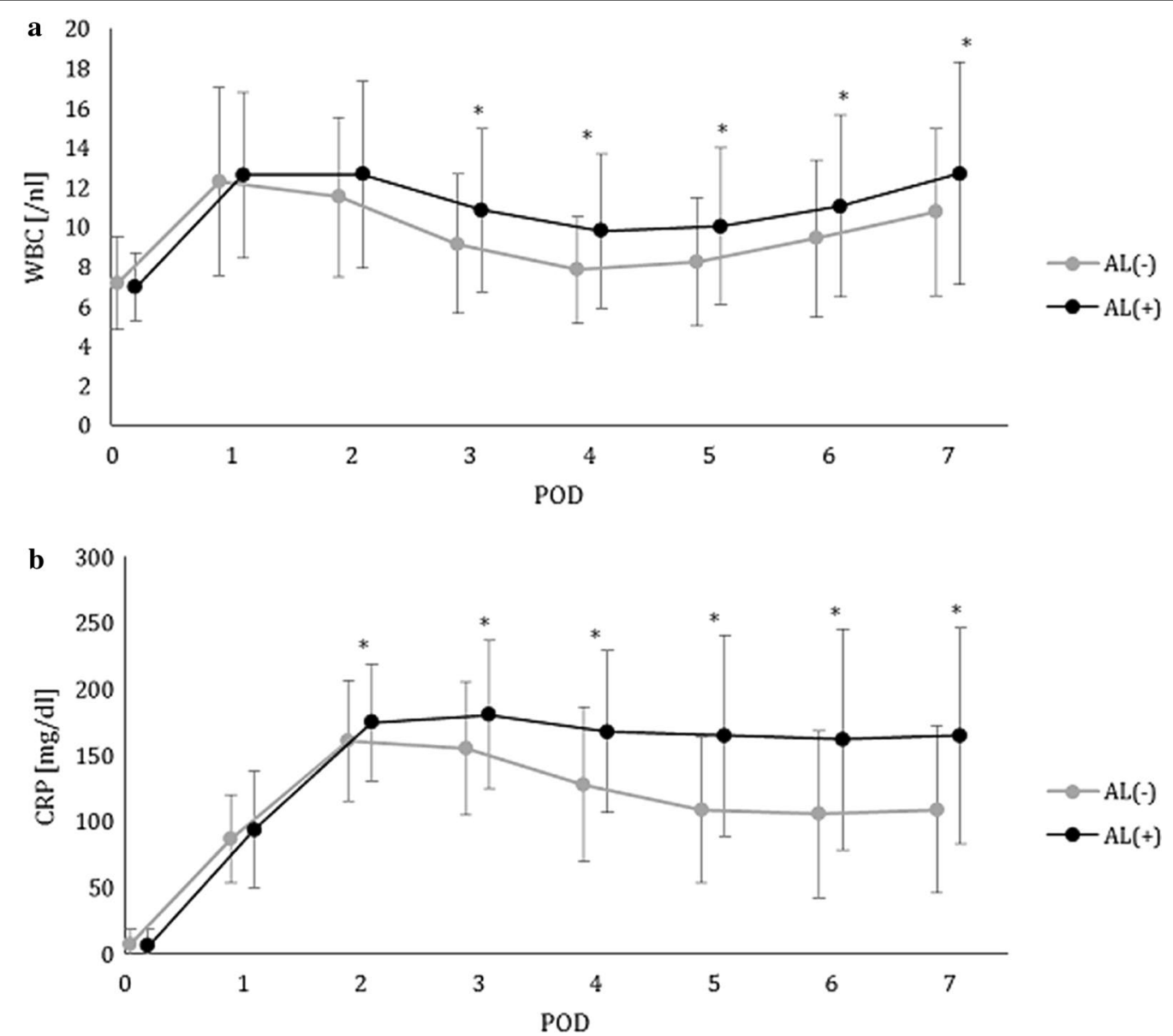

Fig. 2 Pre- and postoperative WBCC (a) and CRP (b) values until the 7th POD after transthoracic esophageal resection. The black and grey lines represent patients with and without anastomotic leakage. Points represent mean values. Error bars show standard deviation. ${ }^{*} p \leq 0.05$

Similar to the evaluation of WBCC, we also evaluated the absolute values and relative changes of CRP in patients with AL 1 to 2 days prior to diagnosis. The CRP showed a mean increase of $26 \%$ (range, $-20 \%$ to $138 \%$ ) and $11 \%$ (range, $-30 \%$ to $119 \%$ ) at 1 and 2 days before diagnosis, respectively. Nevertheless, the CRP values decreased in $38.1 \%$ and in $52 \%$ of the patients on 1 and 2 days prior to AL diagnosis. There were no significant differences in CRP according to the subgroups with and without neoadjuvant treatment (Additional file 1: Table S1 and Additional file 2: Table S2; Fig. 3e, f).

\section{NUn score}

The mean NUn score was significantly different between the AL-negative and the AL-positive groups (8.6 mean (range, 5.2-12.1) vs 9.1 mean (range, 7.5-12.7); $\mathrm{p}=0.006$, Table 3). Depending on the cut-off values, the sensitivity rates ranged from 21 to $79 \%$, while the specificity rates ranged from 25 to $86 \%$, with an AUC of 0.68 (Fig. 3d). The optimal cut-off value of 10 recommended by Noble and Underwood had an NPV of $78.7 \%$ but only a PPV of $31.3 \%$.

\section{Discussion}

Patients who undergo esophageal resection are at risk of developing AL that consequently may lead to life-threatening mediastinitis and sepsis [25, 26, 47]. Therefore, early diagnosis of AL is crucial in further management and therapy $[23,24]$. In colorectal surgery, the CRP level has been shown to be a useful early biomarker of AL [42, 48]. However, the role of CRP-levels as an indicator for $\mathrm{AL}$ after esophageal resection is unclear and preceding studies showed conflicting results. While some studies reported high diagnostic accuracy for CRP-levels predicting and detecting AL in the postoperative course [14, 17], others denied clinical relevance of these measures [34]. Comparably, the diagnostic accuracy of postoperative WBCC for AL remains unclear [10, 15]. In contrast to these two single parameters, the NUn score developed by Noble and Underwood has been reported to have high 
Table 3 Diagnostic accuracy of WBCC and CRP for anastomotic leakage after transthoracic esophageal resection

\begin{tabular}{|c|c|c|c|c|c|c|c|c|c|}
\hline WBCC & POD & AUC & Cut-off [/nl] & Sensitivity & Specificity & NPV & PPV & Accuracy & $p$ value \\
\hline & 0 & $\mathrm{n} / \mathrm{a}$ & $\mathrm{n} / \mathrm{a}$ & $\mathrm{n} / \mathrm{a}$ & $\mathrm{n} / \mathrm{a}$ & $\mathrm{n} / \mathrm{a}$ & $\mathrm{n} / \mathrm{a}$ & $\mathrm{n} / \mathrm{a}$ & 0.984 \\
\hline & 1 & $\mathrm{n} / \mathrm{a}$ & $\mathrm{n} / \mathrm{a}$ & $\mathrm{n} / \mathrm{a}$ & $\mathrm{n} / \mathrm{a}$ & $\mathrm{n} / \mathrm{a}$ & $\mathrm{n} / \mathrm{a}$ & $\mathrm{n} / \mathrm{a}$ & 0.337 \\
\hline & 2 & $\mathrm{n} / \mathrm{a}$ & $\mathrm{n} / \mathrm{a}$ & $\mathrm{n} / \mathrm{a}$ & $\mathrm{n} / \mathrm{a}$ & $\mathrm{n} / \mathrm{a}$ & $\mathrm{n} / \mathrm{a}$ & $\mathrm{n} / \mathrm{a}$ & 0.121 \\
\hline & 3 & 0.65 & 11 & $44 \%$ & $76 \%$ & $82.1 \%$ & $35.1 \%$ & 0.71 & $0.005^{*}$ \\
\hline & 4 & 0.67 & 8 & $64 \%$ & $58 \%$ & $84.6 \%$ & $31.3 \%$ & 0.62 & $0.0005^{*}$ \\
\hline & 5 & 0.55 & 8 & $65 \%$ & $53 \%$ & $83.5 \%$ & $28.9 \%$ & 0.58 & $0.021^{*}$ \\
\hline & 6 & $\mathrm{n} / \mathrm{a}$ & $\mathrm{n} / \mathrm{a}$ & $\mathrm{n} / \mathrm{a}$ & $\mathrm{n} / \mathrm{a}$ & $\mathrm{n} / \mathrm{a}$ & $\mathrm{n} / \mathrm{a}$ & $\mathrm{n} / \mathrm{a}$ & 0.075 \\
\hline & 7 & $\mathrm{n} / \mathrm{a}$ & $\mathrm{n} / \mathrm{a}$ & $\mathrm{n} / \mathrm{a}$ & $\mathrm{n} / \mathrm{a}$ & $\mathrm{n} / \mathrm{a}$ & $\mathrm{n} / \mathrm{a}$ & $\mathrm{n} / \mathrm{a}$ & 0.246 \\
\hline \multirow[t]{9}{*}{ CRP } & POD & AUC & Cut-off [mg/l] & Sensitivity & Specificity & NPV & PPV & Accuracy & $p$ value \\
\hline & 0 & $\mathrm{n} / \mathrm{a}$ & $\mathrm{n} / \mathrm{a}$ & $\mathrm{n} / \mathrm{a}$ & $\mathrm{n} / \mathrm{a}$ & $\mathrm{n} / \mathrm{a}$ & $\mathrm{n} / \mathrm{a}$ & $\mathrm{n} / \mathrm{a}$ & 0.529 \\
\hline & 1 & $\mathrm{n} / \mathrm{a}$ & $\mathrm{n} / \mathrm{a}$ & $\mathrm{n} / \mathrm{a}$ & $\mathrm{n} / \mathrm{a}$ & $\mathrm{n} / \mathrm{a}$ & $\mathrm{n} / \mathrm{a}$ & $\mathrm{n} / \mathrm{a}$ & 0.363 \\
\hline & 2 & $\mathrm{n} / \mathrm{a}$ & $\mathrm{n} / \mathrm{a}$ & $\mathrm{n} / \mathrm{a}$ & $\mathrm{n} / \mathrm{a}$ & $\mathrm{n} / \mathrm{a}$ & $\mathrm{n} / \mathrm{a}$ & $\mathrm{n} / \mathrm{a}$ & 0.075 \\
\hline & 3 & 0.6 & 150 & $72 \%$ & $44 \%$ & $84.3 \%$ & $27.6 \%$ & 0.52 & $0.014^{*}$ \\
\hline & 4 & 0.65 & 145 & $68 \%$ & $63 \%$ & $86.9 \%$ & $35.1 \%$ & 0.91 & $0.0001^{*}$ \\
\hline & 5 & 0.6 & 155 & $46 \%$ & $71 \%$ & $81.6 \%$ & $31.7 \%$ & 0.69 & $0.0001^{*}$ \\
\hline & 6 & 0.53 & 120 & $64 \%$ & $50 \%$ & $82.4 \%$ & $27.4 \%$ & 0.57 & $0.0004^{*}$ \\
\hline & 7 & 0.52 & 140 & $57 \%$ & $51 \%$ & $80 \%$ & $25.5 \%$ & 0.58 & $0.002^{*}$ \\
\hline
\end{tabular}

WBCC: white blood cell count; CRP: C-reactive protein; NUn: Noble and Underwood; POD: postoperative day; AUC: Area under the curve; NPV: negative predictive value; PPV: positive predictive value; n/a: not available

* $p \leq 0.05$

diagnostic accuracy for diagnosing AL after esophageal anastomosis [34]. In light of the mentioned disparity of preceding studies and the clinical relevance of potential early diagnostic markers for AL this monocentric study on 233 patients with esophageal resections aimed at reproducing diagnostic accuracy of CRP and WBCC levels, as well as the NUn score for detecting AL after esophageal resection.

We found significant differences in WBCC between patients with and without $\mathrm{AL}$, but overall diagnostic accuracy did not reach clinical relevance. Although the general decrease of WBCC after the 2nd POD was less profound in patients with AL, optimal diagnostic accuracy was detected on the $4^{\text {th }}$ POD with a cut-off value of $8 / \mathrm{nl}$, which is within the normal range of WBCC. Moreover, $20 \%$ of patients with AL showed also a decrease of WBCC 1 to 2 days prior to diagnosis, indicating missing relevance of these measures for the detection of AL following esophageal resection.

Similarly, we found significant differences in CRP between patients with and without AL with peaking CRP values on the 2nd POD in both groups and decreasing values on the 3rd POD only in the AL-negative group, but AUROCC analysis revealed low sensitivity and specificity rates as well as positive predictive values.

These findings are consistent with those in the literature where a significant difference in CRP level was noted between those with and without AL starting on the 2nd
POD. This early difference in CRP was also observed by van Genderen et al. Hoeboer et al. and Gordon et al. [1618]. In contrast, we could reproduce neither a relevant diagnostic accuracy for detecting AL nor a good PPV or cut-off-level in this study $[12,18]$. Meanwhile, Park et al. reported that the CRP level has improved the diagnosis of AL in the subgroup of patients without neoadjuvant treatment [19]. In contrast, we again could not reproduce these findings in this collective. Analyzing relative percentage changes of CRP in subpopulations with and without neoadjuvant treatment did not reveal better results. One third of patients with AL showed a decrease of CRP 1 to 2 days prior diagnosis in our cohort, which also hampers clinical impact of these diagnostic measures. Therefore, CRP could not be identified as an reliable positive predictive marker and showed low specificity, which is consistent with the findings by Gordon et al. [17]. With respect to the NUn score, which was developed for the detection of AL after upper gastrointestinal surgeries, the reported cut-off values $(>10)$, high sensitivity $(95 \%)$ and modest specificity (49\%), could also not be reproduced in our study. [15, 20,34].

In the present study, the CRP, WBCC, and NUn score did not achieve an AUC of $>0.7$ and are therefore inadequate to be independent markers for detection of AL. Therefore, in contrast to lower GI surgery in patients with esophageal resection inflammatory markers are obviously more influenced by other complications such 

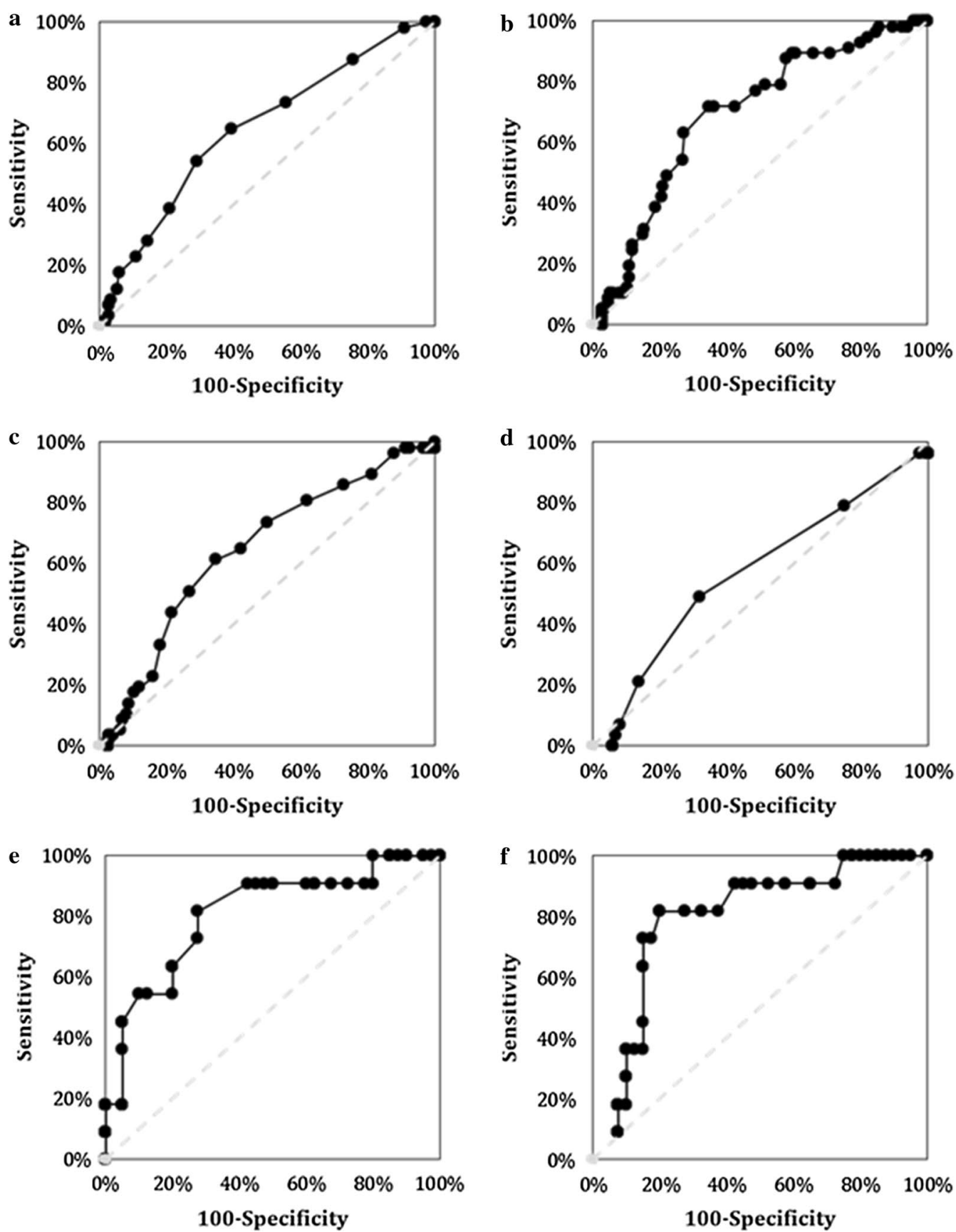

Fig. 3 Receiver operating characteristic (ROC) curves of multivariate logistic regression of WBCC 4th POD (a), CRP 4th POD (b), $\triangle C R P$ 2nd-4th POD (c), NUn score (d), non-neoadjuvant CRP 4th (e), and 5th POD (f) for predicting anastomotic leakage after esophageal resection. True positive rate (sensitivity) is plotted in function of false-positive rate (100-specificity). The closer the graph to the upper left corner, the better the diagnostic accuracy. The area under the ROC curve (AUROCC) indicates the performance of the values for determining anastomotic leakage after esophageal resection. The AUC of WBCC 4th POD is $0.67(p=0.0005)$; CRP 4th POD, $0.65(p<0.0001)$; $\triangle C R P$ 2nd-4th POD, $0.62(p=0.0003)$; NUn score, 0.68 $(p=0.004)$; and non-neoadjuvant CRP 4th POD, $0.68(p=0.01)$ and 5th POD, $0.67(p=0.0009)$

as pneumonia and cannot serve as independent markers. But we found CRP to be an accurate negative predictive marker: for CRP levels below $155 \mathrm{mg} / \mathrm{dl}$ from POD 3 to POD 7 the negative predictive value for absence of AL was $>80 \%$. The best accuracy for CRP was on 4 th POD with a cut-off value of $145 \mathrm{mg} / \mathrm{l}$, which implies that 9 out of 10 patients with CRP level $<145 \mathrm{mg} / \mathrm{l}$ on the 4th POD do not have AL. Therefore, this study indicates that 
Table 4 Diagnostic accuracy of absolute alteration of WBCC and CRP for anastomotic leakage after transthoracic esophageal resection

\begin{tabular}{|c|c|c|c|c|c|c|c|c|c|}
\hline WBCC & $\triangle \mathrm{POD}$ & AUC & Cut-off [/nl] & Sensitivity & Specificity & NPV & PPV & Accuracy & $p$ value \\
\hline & 0 to 2 & 0.6 & 3 & $78 \%$ & $36 \%$ & $85 \%$ & $26 \%$ & 0.48 & 0.052 \\
\hline & 2 to 3 & 0.67 & $\mathrm{n} / \mathrm{a}$ & $\mathrm{n} / \mathrm{a}$ & $\mathrm{n} / \mathrm{a}$ & $\mathrm{n} / \mathrm{a}$ & $\mathrm{n} / \mathrm{a}$ & $\mathrm{n} / \mathrm{a}$ & 0.17 \\
\hline & 3 to 4 & 0.62 & $\mathrm{n} / \mathrm{a}$ & $\mathrm{n} / \mathrm{a}$ & $\mathrm{n} / \mathrm{a}$ & $\mathrm{n} / \mathrm{a}$ & $\mathrm{n} / \mathrm{a}$ & $\mathrm{n} / \mathrm{a}$ & 0.285 \\
\hline & 4 to 5 & 0.5 & $\mathrm{n} / \mathrm{a}$ & $\mathrm{n} / \mathrm{a}$ & $\mathrm{n} / \mathrm{a}$ & $\mathrm{n} / \mathrm{a}$ & $\mathrm{n} / \mathrm{a}$ & $\mathrm{n} / \mathrm{a}$ & 0.121 \\
\hline & 5 to 6 & 0.44 & $\mathrm{n} / \mathrm{a}$ & $\mathrm{n} / \mathrm{a}$ & $\mathrm{n} / \mathrm{a}$ & $\mathrm{n} / \mathrm{a}$ & $\mathrm{n} / \mathrm{a}$ & $\mathrm{n} / \mathrm{a}$ & 0.379 \\
\hline \multirow[t]{7}{*}{ CRP } & $\triangle \mathrm{POD}$ & AUC & Cut-off [mg/l] & Sensitivity (\%) & Specificity (\%) & NPV (\%) & PPV (\%) & Accuracy & $p$ value \\
\hline & 1 to 3 & 0.57 & 90 & 48 & 63 & 80.5 & 27.9 & 0.64 & $0.011^{*}$ \\
\hline & 2 to 3 & 0.59 & 0 & 54 & 61 & 81.7 & 29 & 0.64 & $0.024^{*}$ \\
\hline & 2 to 4 & 0.62 & -20 & 5 & 63 & 83.5 & 31.6 & 0.66 & $0.0003^{*}$ \\
\hline & 3 to 4 & 0.63 & -20 & 60 & 61 & 83.7 & 31 & 0.65 & $0.0001^{*}$ \\
\hline & 2 to 5 & 0.59 & -50 & 68 & 51 & 84.3 & 29 & 0.59 & $0.00001^{*}$ \\
\hline & 3 to 5 & 0.59 & -10 & 44 & 75 & 81.9 & 34.1 & 0.72 & $0.00008^{*}$ \\
\hline
\end{tabular}

WBCC: white blood cell count; CRP: C-reactive protein; NUn: Noble and Underwood; $\triangle P O D$ : change of value (WBCC or CRP) between postoperative days; AUC: Area under the curve; NPV: negative predictive value; PPV: positive predictive value; $n / a$ : not available

* $p \leq 0.05$

serum CRP concentration measured on the 4th to the 7th POD is a useful negative predictive marker for the development of $\mathrm{AL}$, which may be helpful in postoperative patient management as these patients might be discharged earlier [17].

The retrospective nature of this study and variability in neoadjuvant treatments are indeed limitations of this study; otherwise, our cohort is homogenous, including only patients who underwent transthoracic esophageal resection. In order to improve detection and in sufficient time management of postoperative esophageal leakage, further prospective studies are needed to investigate new and better prognostic markers.

\section{Conclusions}

The investigated inflammatory markers WBCC, CRP, and NUn score could not be identified as independent predictive markers of AL in the present study. But CRP values $<155 \mathrm{mg} / \mathrm{l}$ on the $3 \mathrm{rd}$ to 7 th POD showed an acceptable performance as a negative predictor for $\mathrm{AL}$ and this discrimination of AL and no-AL maybe helpful for the postoperative clinical management.

\section{Supplementary Information}

The online version contains supplementary material available at https://doi. org/10.1186/s12893-020-00995-2.

Additional file 1: Table S1. Diagnostic accuracy of WBCC and CRP for anastomotic leakage after transthoracic esophageal resection in patients without neoadjuvant treatment.

Additional file 2: Table S2. Diagnostic accuracy of WBCC and CRP for anastomotic leakage after transthoracic esophageal resection in patients with neoadjuvant treatment.

\section{Abbreviations}

AL: Anastomotic leakage; AUC: Area under the curve; AUROCC: Area under the receiver operating characteristics curve; CRP: C-reactive protein; NPV: Negative predictive value; NUn: Noble and Underwood; POD: Postoperative day; PPV: Positive predictive value; WBCC: White blood cell count.

\section{Acknowledgements}

None.

\section{Authors' contributions}

LFL contributed to the conception, design, data collection, data analysis, and article preparation. PS, MD, TS, BP M-S, TH, and MWB contributed to article review. UH contributed to data analysis and article review. AS contributed to the study conception and article preparation. All authors read and approved the final manuscript.

Funding

Open Access funding enabled and organized by Projekt DEAL.

Availability of data and materials

The datasets generated and/or analyzed during the current study are not publicly available due to patient privacy and security of electronic medical information but are (anonymized) available from the corresponding author on reasonable request.

\section{Ethics approval and consent to participate}

The study was approved by the Ethical Committee of the Medical Faculty Heidelberg (S635-2013). Need for written informed consent was waived owing to the retrospective nature of the study.

Consent for publication

Not applicable as there is no identifiable material in this manuscript.

\section{Competing interests}

The authors declare that they have no competing interests.

\section{Author details}

${ }^{1}$ Department of Surgery, Heidelberg University Hospital, Im Neuenheimer Feld 420, 69120 Heidelberg, Germany. ${ }^{2}$ Department of Gastroenterology, Heidelberg University Hospital, Im Neuenheimer Feld 410, 69120 Heidelberg, Germany. 
Received: 17 August 2020 Accepted: 1 December 2020

Published online: 09 December 2020

\section{References}

1. Campbell NP, Villaflor VM. Neoadjuvant treatment of esophageal cancer. World J Gastroenterol. 2010;16:3793-803.

2. Dimick JB, Wainess RM, Upchurch GR, lannettoni MD, Orringer MB. National trends in outcomes for esophageal resection. Ann Thorac Surg. 2005;79:212-6.

3. Takahashi C, Shridhar R, Huston J, Meredith K. Esophagectomy from then to now. J Gastrointest Oncol. 2018;9:903-9.

4. Kohn GP, Galanko JA, Meyers MO, Feins RH, Farrell TM. National trends in esophageal surgery-are outcomes as good as we believe? J Gastrointest Surg. 2009;13:1900-12.

5. Van Jan B, Lanschot J, Hulscher JBF, Buskens CJ, Tilanus HW, Ten Kate FJW, Obertop H. Hospital volume and hospital mortality for esophagectomy. Cancer. 2001;91:1574-8

6. Migliore M, Choong CK, Lim E, Goldsmith KA, Ritchie A, Wells FC. A surgeon's case volume of oesophagectomy for cancer strongly influences the operative mortality rate. Eur J Cardio-thoracic Surg. 2007;32:375-80.

7. Metzger R, Bollschweiler E, Vallböhmer D, Maish M, DeMeester TR, Hölscher AH. High volume centers for esophagectomy: What is the number needed to achieve low postoperative mortality? Dis Esophagus. 2004;17:310-4.

8. Baltin CT, Bludau M, Kron F, Zander T, Hallek M, Hölscher AH, Schröder W. Profit-Center-Analyse der ÖsophagektomieProfit center analysis of esophagectomy. Der Chir. 2018;89:229-36.

9. Nimptsch U, Haist T, Krautz C, Grützmann R, Mansky T, Fallzahl LD. Krank enhaussterblichkeit und Komplikationsmanagement in der Ösophaguschirurgie. Dtsch Aerzteblatt Online. 2018. https://doi.org/10.3238/ arztebl.2018.0793.

10. Deitmar S, Anthoni C, Palmes D, Haier J, Senninger N, Brüwer M. Sind leukozyten und $\mathrm{C}$-reaktives protein geeignete parameter als frühindikatoren der anastomosen-insuffizienz nach ösophagusresektion? Zentralblatt fur Chir Zeitschrift fur Allg Visz und Gefasschirurgie. 2009;134:83-9.

11. Rizk NP, Bach PB, Schrag D, Bains MS, Turnbull AD, Karpeh M, Brennan MF, Rusch VW. The impact of complications on outcomes after resection for esophageal and gastroesophageal junction carcinoma. J Am Coll Surg. 2004;198:42-50

12. Warschkow R, Tarantino I, Ukegjini K, Beutner U, Müller SA, Schmied BM, Steffen T. Diagnostic study and meta-analysis of C-reactive protein as a predictor of postoperative inflammatory complications after gastroesophageal cancer surgery. Langenbeck's Arch Surg. 2012;397:727-36.

13. Bardini R, Bonavina L, Asolati M, Ruol A, Castoro C, Tiso E. Single-layered cervical esophageal anastomoses: a prospective study of two suturing techniques. Ann Thorac Surg. 1994;58:1087-9.

14. Dutta S, Fullarton GM, Forshaw MJ, Horgan PG, McMillan DC. Persistent elevation of C-reactive protein following esophagogastric cancer resection as a predictor of postoperative surgical site infectious complications. World J Surg. 2011;35:1017-25.

15. Findlay JM, Tilson RC, Harikrishnan A, Sgromo B, Marshall REK, Maynard ND, Gillies RS, Middleton MR. Attempted validation of the NUn score and inflammatory markers as predictors of esophageal anastomotic leak and major complications. Dis Esophagus. 2015;28:626-33.

16. Van Genderen ME, Lima A, De Geus H, Klijn E, Wijnhoven B, Gommers D, Van Bommel J. Serum C-reactive protein as a predictor of morbidity and mortality in intensive care unit patients after esophagectomy. Ann Thorac Surg. 2011;91:1775-9.

17. Gordon AC, Cross AJ, Foo EW, Roberts RH. C-reactive protein is a useful negative predictor of anastomotic leak in oesophago-gastric resection. ANZ J Surg. 2018;88:223-7.

18. Hoeboer SH, Groeneveld ABJ, Engels N, van Genderen M, Wijnhoven $B P L$, van Bommel J. Rising C-reactive protein and procalcitonin levels precede early complications after esophagectomy. J Gastrointest Surg. 2015;19:613-24

19. Park JK, Kim JJ, Moon SW. C-reactive protein for the early prediction of anastomotic leak after esophagectomy in both neoadjuvant and non-neoadjuvant therapy case: a propensity score matching analysis. J Thorac Dis. 2017;9:3693-702.

20. Paireder M, Jomrich G, Asari R, Kristo I, Gleiss A, Preusser M, Schoppmann SF. External validation of the NUn score for predicting anastomotic leakage after oesophageal resection. Sci Rep. 2017;7:9725.

21. Campbell WB. Proposed definitions for the audit of postoperative infection: a discussion paper. Ann R Coll Surg Engl. 1992:74:151.

22. Lerut T, Coosemans W, Decker G, De Leyn P, Nafteux P, Van Raemdonck D. Anastomotic complications after esophagectomy. Dig Surg. 2002;19:92-8.

23. Férard G, Bourguignat A, Ingenbleek Y. C-reactive protein to transthyretin ratio for the early diagnosis and follow-up of postoperative infection. Clin Chem Lab Med. 2002;40:1334-8.

24. Kofoed K, Schneider UV, Scheel T, Andersen O, Eugen-Olsen J. Development and validation of a multiplex add-on assay for sepsis biomarkers using xMAP technology. Clin Chem. 2006:52:1284-93.

25. Pierce T. Acute mediasinitis. BUMC Proc. 2000;13:31-3.

26. Bitkover CY, Vaage J, Ga B. Postoperative mediastinitis in cardiac surgery - microbiology and pathogenesis. Eur J Cardio-Thoracic Surg 2002:21:825-30.

27. Sauvanet A, Baltar J, Le Mee J, Belghiti J. Diagnosis and conservative management of intrathoracic leakage after oesophagectomy. Br J Surg. 1998;85:1446-9.

28. Schaible A, Brenner T, Hinz U, Schmidt T, Weigand M, Sauer P, Büchler MW, Ulrich A. Significant decrease of mortality due to anastomotic leaks following esophageal resection: management makes the difference. Langenbeck's Arch Surg. 2017:402:1167-73.

29. Griffin SM, Lamb PJ, Dresner SM, Richardson DL, Hayes N. Diagnosis and management of a mediastinal leak following radical oesophagectomy. $\mathrm{Br}$ J Surg. 2001;88:1346-51.

30. Mardin WA, Palmes D, Bruewer M. Current concepts in the management of leakages after esophagectomy. Thoracic Cancer. 2012. https://doi.org/ 10.1111/j.1759-7714.2012.00117.x.

31. Turkyilmaz A, Eroglu A, Aydin Y, Tekinbas C, Muharrem Erol M, Karaoglanoglu N. The management of esophagogastric anastomotic leak after esophagectomy for esophageal carcinoma. Dis Esophagus. 2009;22:119-26.

32. Junemann-Ramirez M, Awan MY, Khan ZM, Rahamim JS. Anastomotic leakage post-esophagogastrectomy for esophageal carcinoma: Retrospective analysis of predictive factors, management and influence on longterm survival in a high volume centre. Eur J Cardio Thoracic Surg. 2005;27:3-7.

33. Tsujimoto H, Ono S, Takahata R, Hiraki S, Yaguchi Y, Kumano I, Matsumoto Y, Yoshida K, Aiko S, Ichikura T, Yamamoto J, Hase K. Systemic inflammatory response syndrome as a predictor of anastomotic leakage after esophagectomy. Surg Today. 2012;42:141-6.

34. Noble F, Curtis N, Harris S, Kelly JJ, Bailey IS, Byrne JP, Underwood TJ. Risk assessment using a novel score to predict anastomotic leak and major complications after oesophageal resection. J Gastrointest Surg. 2012;16:1083-95

35. Baker EH, Hill JS, Reames MK, Symanowski J, Hurley SC, Salo JC. Drain amylase aids detection of anastomotic leak after esophagectomy. J Gastrointest Oncol. 2016:7(2):181-8.

36. Asti E, Bonitta G, Melloni M, Tornese S, Milito P, Sironi A, Costa E, Bonavina L. Utility of $C$-reactive protein as predictive biomarker of anastomotic leak after minimally invasive esophagectomy. Langenbeck's Arch Surg. 2018;403(2):235-44

37. Gao C, Xu G, Wang C, Wang D. Evaluation of preoperative risk factors and postoperative indicators for anastomotic leak of minimally invasive Mckeown esophagectomy: a single-center retrospective analysis. J Cardiothorac Surg. 2019;14(1):1-8

38. Bundred J, Hollis AC, Hodson J, Hallissey MT, Whiting JL, Griffiths EA Validation of the NUn score as a predictor of anastomotic leak and major complications after esophagectomy. Dis Esophagus. 2020;33(1):1-9.

39. Nilsson E, Johansson J, Falkenback D, Jeremiasen M, Åkesson O, Hermansson M. Predicting anastomotic leakage after esophagectomy: the value of C-reactive protein. A nationwide register study. Dis Esophagus. 2018;31:182.

40. Straatman J, Cuesta MA, Tuynman JB, Veenhof AAFA, Bemelman WA, van der Peet DL. C-reactive protein in predicting major postoperative complications are there differences in open and minimally invasive colorectal 
surgery? Substudy from a randomized clinical trial. Surg Endosc. 2018;32:2877-85.

41. Du Clos TW. Function of C-reactive protein. Ann Med. 2000;32:274-8.

42. Almeida AB, Faria G, Moreira H, Pinto-de-Sousa J, Correia-da-Silva P, Maia JC. Elevated serum C-reactive protein as a predictive factor for anastomotic leakage in colorectal surgery. Int J Surg. 2012;10:87-91.

43. Waterland P, Ng J, Jones A, Broadley G, Nicol D, Patel H, Pandey S. Using CRP to predict anastomotic leakage after open and laparoscopic colorectal surgery: is there a difference? Int J Colorectal Dis. 2016:31:861-8.

44. Edagawa E, Matsuda Y, Gyobu K, Lee S, Kishida S, Fujiwara Y, Hashiba R, Osugi H, Suehiro S. C-reactive protein is a useful marker for early prediction of anastomotic leakage after esophageal reconstruction. Osaka City Med J. 2015;61(1):53-61.

45. Zweig MH, Campbell G. Receiver-operating characteristics (ROC) plots - a fundamental evaluation tool in clinical medicine. Clin Chem. 1993:39:561-77.
46. Mandrekar JN. Receiver operating characteristic curve in diagnostic test assessment. J Thorac Oncol. 2010;5:1315-6.

47. Bartels H, Siewert JR. Therapie der Mediastinitis am Beispiel des Ösophaguskarzinoms. Chirurg. 2008;79:30-7.

48. Gans SL, Atema JJ, van Dieren S, Koerkamp BG, Boermeester MA. Diagnostic value of $C$-reactive protein to rule out infectious complications after major abdominal surgery: a systematic review and meta-analysis. Int J Colorectal Dis. 2015;30:861-73.

\section{Publisher's Note}

Springer Nature remains neutral with regard to jurisdictional claims in published maps and institutional affiliations.
Ready to submit your research? Choose BMC and benefit from:

- fast, convenient online submission

- thorough peer review by experienced researchers in your field

- rapid publication on acceptance

- support for research data, including large and complex data types

- gold Open Access which fosters wider collaboration and increased citations

- maximum visibility for your research: over $100 \mathrm{M}$ website views per year

At BMC, research is always in progress.

Learn more biomedcentral.com/submissions 